\title{
Modern Geodetic Measurement Techniques in Gravimetric Studies on the Example of Gypsum Karst in the Siesławice Region
}

\author{
Stawomir Porzucek ${ }^{1, *}$, Monika Łój ${ }^{1}$, Karolina Matwij $^{2}$, and Wojciech Matwij $^{2}$ \\ ${ }^{1}$ AGH University of Science and Technology, Faculty of Geology, Geophysics and Environmental \\ Protection, A. Mickiewicza Av. 30, 30-059 Krakow, Poland \\ ${ }^{2}$ AGH University of Science and Technology, Faculty of Mining Surveying and Environmental \\ Engineering, A. Mickiewicza Av. 30, 30-059 Krakow, Poland
}

\begin{abstract}
In the region of Siesławice (near Busko-Zdrój, Poland) there are unique phenomena of gypsum karst. Atmospheric factors caused numerous gypsum outcrops, canals and underground voids. The article presents the possibility of using non-invasive gravimetric surveys supplemented with geodetic measurements to illustrate karst changes occurring around the void. The use of modern geodetic measurement techniques including terrestrial and airborne laser scanning enables to generate a digital terrain model and a three-dimensional model of voids. Gravimetric field studies allowed to map the anomalies of the gravitational field of the near-surface zone. Geodetic measurement results have made it possible to accurately determine the terrain correction that supplemented the gravimetric anomaly information. Geophysical interpretation indicate the presence of weathered rocks in the near surface zone and fractures and loosened zones located surround the karst cave. Key words - karst, gravimetry, geodesy, terrain correction, laser scanning.
\end{abstract}

\section{Introduction}

Gravity and geodetic survey was carried out in "Cave in Siesławice" area. It is located in rod-like gypsum crystals and sabre-like gypsum crystals layer of Miocene age. It has a bell shape cross-section and according to the 2013 study its length is $17 \mathrm{~m}$ and its roof is $2 \mathrm{~m}$ deep below ground level [7]. It is partially filled with water (Fig. 1). The area around the profiles had a complicated topography. There were a lot sinkholes and slopes close by and on the profiles.

The aim of the study was to detect any cavities and loosened zones over and near the cave, the existence of which may threaten the stability of the cave. To make this possible it was necessary to maintain high accuracy measurements with gravimetric measurements and eliminating adverse factors affecting the measured values of gravity. These factors were the relief of the terrain and the cave itself. To eliminate gravitational influence of both factors,

* Corresponding author: porzucek@agh.edu.pl 
accurate geodetic measurements were required. Therefore, the latest terrestrial laser scanning (TLS) and airborne laser scanning (ALS) techniques have been used.

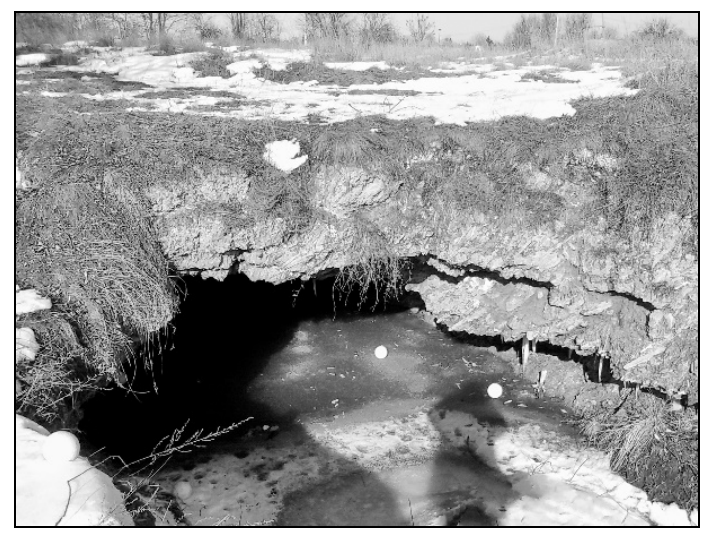

Fig. 1. "Cave in Siesławice"

\section{Geological settings}

"Cave in Sieslawice" is located in layer of evaporates (gypsum) in Miocene series, in the Nida Gypsum cave sub-region of Busko Staszów [3, 9]. The layer of evaporates has a significant thickness $(40 \mathrm{~m})$ and is built of four main parts. In the footwall part there is a glassy gypsum (3.5 4 m thickness) with large crystal intergrowths. It is covered by $3 \mathrm{~m}$ thickness fine-crystalline gypsum. The next part is composed as rod-like gypsum crystals and sabre-like gypsum crystals. The last evaporate layer is laminated and detrital gypsum [5].

All karst caves, in this area are most often found in layer of rod-like gypsum crystals and sabre-like gypsum crystals but also in the layer of glassy gypsum. Because of the different structure of these two layers, caves of various shapes and durability are formed. Caves of glassy gypsum layer are most often trapezoidal and do not often collapse. Caves of rod-like gypsum crystals and sabre-like gypsum crystals layer have bells and lenticular shapes resulting from the scattering and collapse of their roof part [10]. In the roof part of evaporate layer the cavers are very rare, which is related to their very rapid collapse.

\section{Methodology of gravimetric and geodetic measurements}

The application of the gravimetric method was used due to the fact that the most contrasting physical parameter in the tested area was the bulk density. This method takes an advantage of the variability of the Earth gravitational field, depending on its structure. Every heterogeneity in the rock mass density distribution generates its own gravitational field. Such heterogeneity are, for example, various geological structures and anthropogenic forms such as faults, voids, mines shaft or drifts [4]. It means that in the first instance the gravity distribution depends on difference of rock mass bulk density, but also from the size, shape and depth of occurrence of this heterogeneity [8].

Gravimetric survey was made using the intermediate points method. The size of the study area and the number of measuring points determined the choice of one basic point. It was located in the studied area. This location provides stable conditions for conducting gravimetric cyclic (every 1 hour) to control gravimeter drift.

Gravimetric surveys was carried out using a CG-5 Autograv gravimeter by the Canadian company Scintrex. Measurement accuracy of this gravimeter is $0.005 \mathrm{mGal}$, with repeatability 
of $0.001 \mathrm{mGal}$. At each measuring point the observations were taken twice to avoid random error.

After field observations and their initial processing, the Bouguer anomaly values were calculated for all measuring points. Terrain relief requires the calculation of the terrain correction and the existence of a cave partially filled with water requires the calculation of the "cave correction" [1]. This meant the need for additional geodetic surveys that were carried out using new geodetic techniques.

Gravimetric studies are always supplemented by geodetic measurements. They generally refer to the spatial coordinates of the measuring points and to create a digital model of the surveyed area. In the analyzed case a number of modern measuring technologies were used, which allowed to generate the shape of both the research object and its surrounding region. Geodetic field measurements included the use of classical (tachymetry) as well as modern (terrestrial laser scanning TLS) measurement technology. These measurements have also been supplemented by a digital model of surface area derived from airborne laser scanning ALS. For this purpose, a surface model derived from a CODGiK resource at a resolution of 1 point $/ \mathrm{m}^{2}$ was taken. Tachymetric measurements included the execution of several profiles that were positioned so that their center was approximately over the void. The area of the study terrain was $500 \mathrm{~m}^{2}$ where five gravimetric profile were made. Due to the shape of the terrain and the most accurate mapping of the gravimetric anomaly, the distance between the profile points was about $2 \mathrm{~m}$ (further away from the cave) and $1 \mathrm{~m}$ in the part above the cave. Tachymetric measurements were carried out in the local coordinate system created for the object of research. The later transformation of the local system to the Polish coordinate system "1992" allowed the data from three measurement technologies to be linked together.

\section{Geodesy TLS and ALS}

One of the most important tasks required to precisely design a topographic correction is a faithful and detailed mapping of the terrain. For this purpose, TLS technology has been used to achieve a dense model of terrain around a void of resolution of several thousand dots per square meter [2]. Due to the small size and high speed Faro Focus 3D scanner was applied, which makes it ideal for measurements both on the surface and underground excavations [6]. To create a model of the surface area around the void scans from 9 positions were made, and to create a 3D model of the cave, because of its small size three scan were sufficient. The height of the cave did not exceed $1 \mathrm{~m}$ in many places, so inside of the cave scanner was only placed on the tribrach (Fig. 2). This was possible because the bottom surface of the cave was covered with a thick layer of ice.

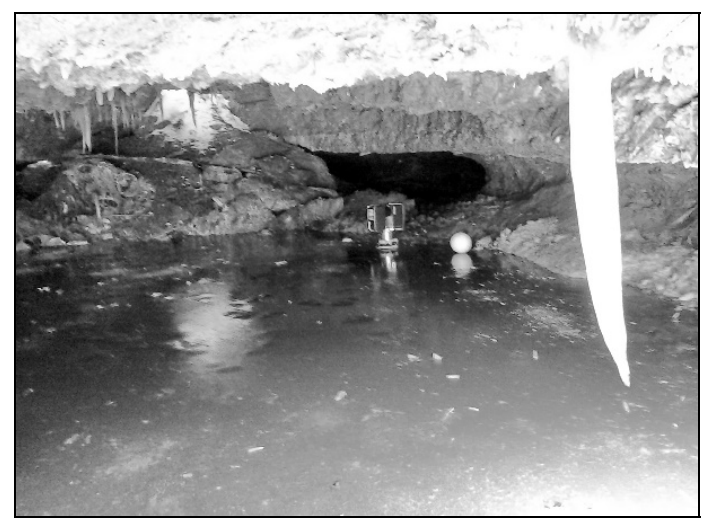

Fig. 2. Photo of cave interior during scanner operation 
To register scans usually checkboard targets and spheres were used but in difficult areas a cloud to cloud option was also applied. The registration process was carried out in Leica Cyclone 9.1. The mean absolute error for the used targets in the registration process was $4 \mathrm{~mm}$, which may indicate the correctness of the process itself and its high precision. Due to the small range of the scanner, a dense measurement has covered the area over the emptiness and about $25 \mathrm{~m}$ around it. Correct definition of the topographic correction value required information from a larger area. The data needed for this purpose were imported from the digital model of the surface from the ALS technology (Fig. 3). Transformation the measurement data from local coordinate system into a global one made it possible to create a complete and detailed surface model with sufficient accuracy.

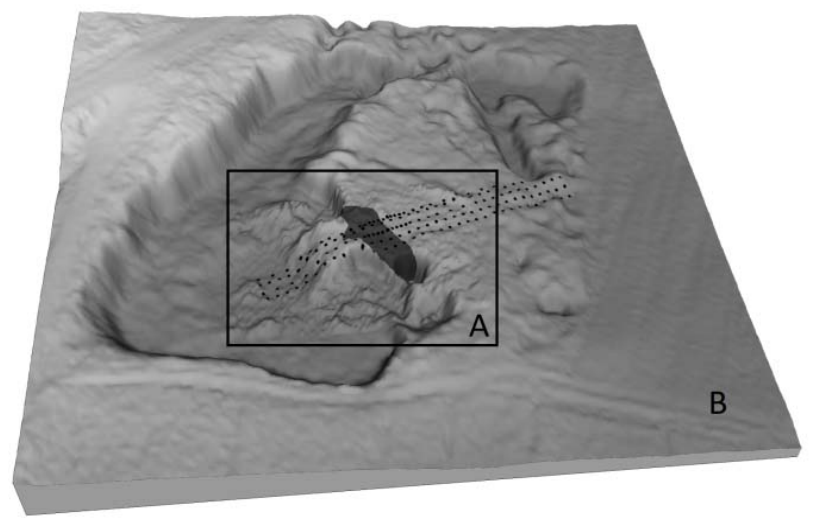

Fig. 3. Digital terrain model (DTM) based on integrated data derived from TLS (A) and ALS (B) measurements. The profile points are marked with black dots, the location of the cave is shown in a darker shade

Transformation parameters were calculated during cloud to cloud process of both TLS and ALS terrain measurements. The same transformation parameters were applied to the point cloud representing the interior of the cave. Next step was to unify the point cloud to a resolution of $25 \mathrm{~mm}$ and exported it to Geomagic Qualify. In this program a continuous vector model was created and on its basis cross sections with a gap of $10 \mathrm{~cm}$ (Fig. 4) were made.

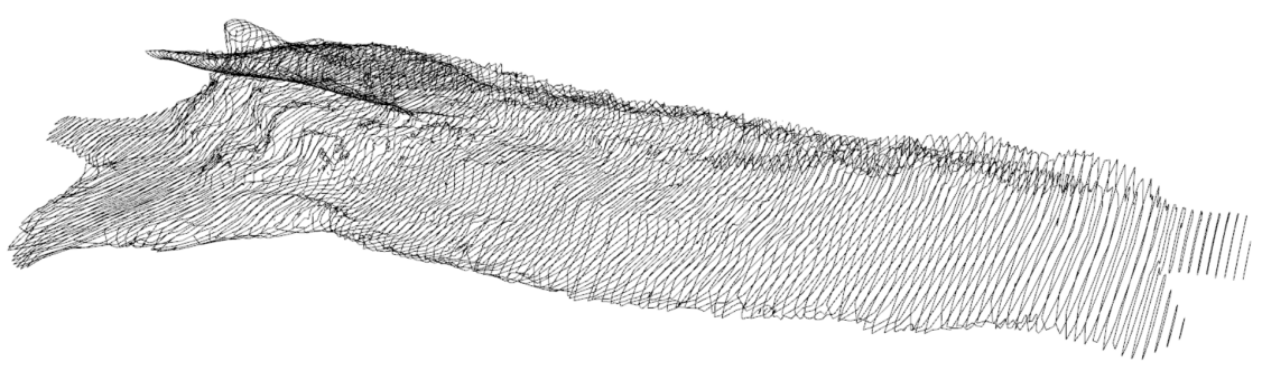

Fig. 4. Spatial model of the cave presented in cross-sections with a gap of $10 \mathrm{~cm}$

\section{Terrain correction}

Detecting any cracks above the cave or loosened zones in the overlay requires that the gravimetric survey has the measuring error as small as possible. The gravity influence of a terrain relief is one of the significant the error, which can be eliminated by the terrain 
correction. By analysing the position of measuring points against the background of the relief (Fig. 3), it is easy to see that some of the points are located close to a significant depression of the terrain and even on the scarp. For this reason, it was necessary to calculate a terrain correction. For this purpose, digital numeric model was used, which was obtained from terrestrial and airborne laser scanning. A program from Geosoft's Oasis montaj package was used for calculation the terrain correction, with density equal $2.3 \mathrm{~g} \cdot \mathrm{cm}^{3}$. This density was similar to the average density of gypsum. The terrain correction was calculated by collecting terrain data from a radius of $50 \mathrm{~m}$ around each measuring point (Fig. 3). Increasing radius did not significantly alter relative changes in correction values.

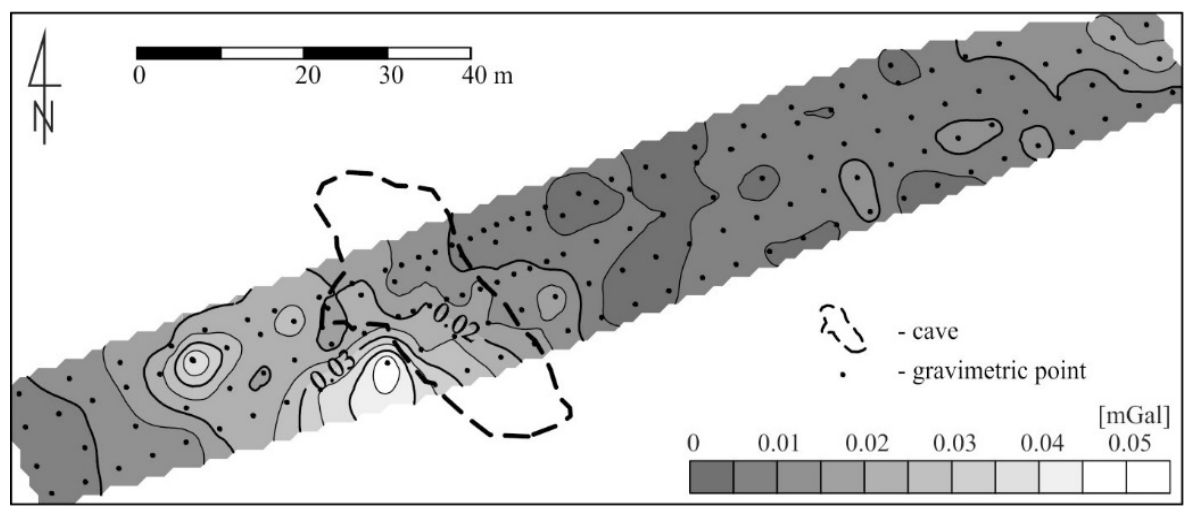

Fig. 5. Distribution of terrain correction

As expected, the terrain correction has achieved its greatest value in the region of the scarp. The maximum values were about $0.049 \mathrm{mGal}$ and were significant in proportion to expected effects from possible voids, cracks and loosened zones.

\section{Cave elimination}

To be able to observe possible changes in the rocks around and above the cave, it was necessary to calculate the "cave correction", which gravitational influence of "Cave in Siesławice". For this reason, it was necessary to determine the geometry of the cave and its relative position to measuring points. In a survey carried out in 2013 [7] the cave geometry was determined by a tachymeter. Due to difficult measurement conditions the cave shape was very approximate. The entire cave was flooded with a depth of about $1 \mathrm{~m}$, which made it impossible to enter and perform accurate observations. In the next phase of the study, the survey was made in the winter, when water was frozen. This made it possible to enter the cave. The modern geodetic laser scanning techniques were used to accurately reflect the shape of the cave (Fig. 4).

There were two parts of "cave correction": one was the correction of the empty cave (void), and the second is the correction of the water-filled cave (cavity). As show in Figure 4 the cave shape was very irregular, which made it difficult to calculate the correction. In the calculation, the method described by Gołębiowski 2016 [1], was used. In this method, the complex spatial body is divides into slices of specified thickness, which makes calculations of the correction much easier.

Based on a few measurements, the water depth at the bottom of the cave was determined. It allowed to create a model of water and to calculate the second part of the correction. Both of them, the cave and water had a bulk density much smaller than the surrounding gypsum 
rocks, so they reduced measured gravity value. For this reason the correction has a positive value (Fig. 6).

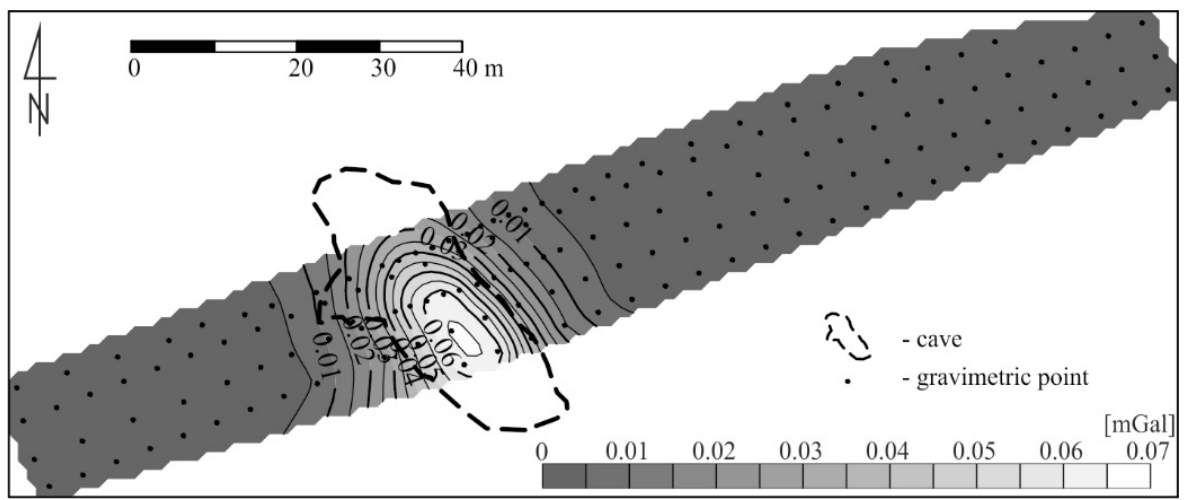

Fig. 6. Distribution of the "cave correction"

Of course, the greatest values were observed directly above the cave, which were decreasing rapidly at a distance from it. The values obtained from the calculation were significant and had a noticeable impact on the measured values. Of course, the highest correction value was obviously from the empty part of the cave (max. $0.047 \mathrm{mGal}$ ), while water correction was only max. $0.019 \mathrm{mGal}$. The analysis shows that the error of void correction did not exceed $\pm 3 \%$ and for water $\pm 5 \%$.

\section{Interpretation}

Bouguer anomaly values were a base on the interpretation of gravimetric surveys. In the first step, they were calculated from the simple Bouguer anomaly formula, which means that only free-air correction and Bouguer correction were included. There is a distribution of this anomaly in Figure 7.

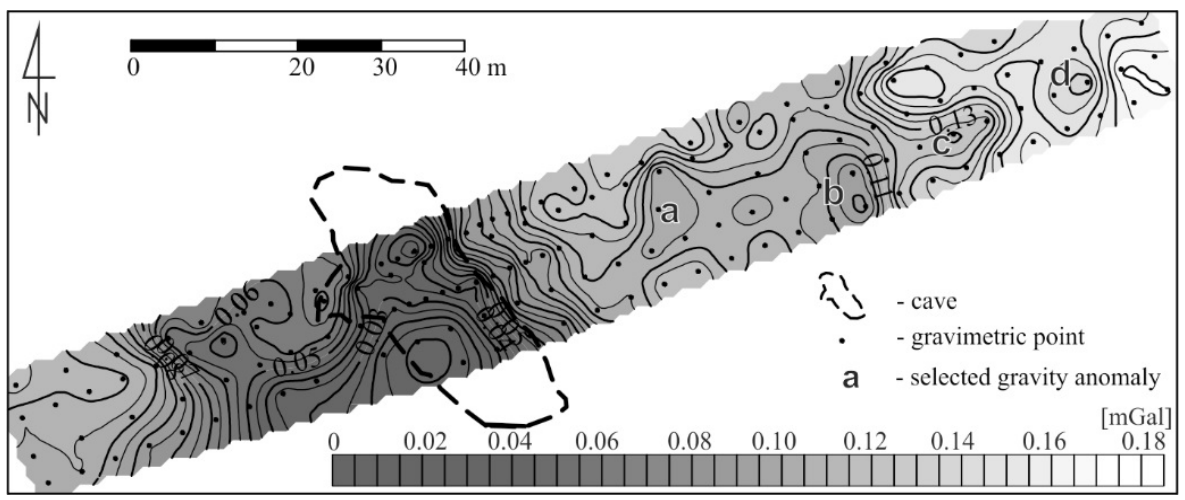

Fig. 7. Distribution of Bouguer anomalies

By analyzing the distribution, there are large variations in Bouguer anomaly values throughout the study area. This clearly demonstrates that the karst processes are responsible for the strong diversity of the bulk density of near-surface rocks. The largest changes in values are observed above the cave and on the scarp on SW from the cave. It means that a large part of these disturbances come from the cave and the scarp. There are also four minor, relatively negative anomalies $(\mathrm{a}, \mathrm{b}, \mathrm{c}, \mathrm{d})$ in the NE of the test area. 
In the next step, a terrain correction was taken into account (Fig. 8). It has effectuated significant changes in Bouguer anomalies distribution in the scarp area, and minor changes in the rest of this distribution. There were still an area of relatively negatives anomalies in SW part of the survey area. Undoubtedly they were caused by the existence of the cave. The minor a, b, c and d anomalies were still visible but have slightly changed shape.

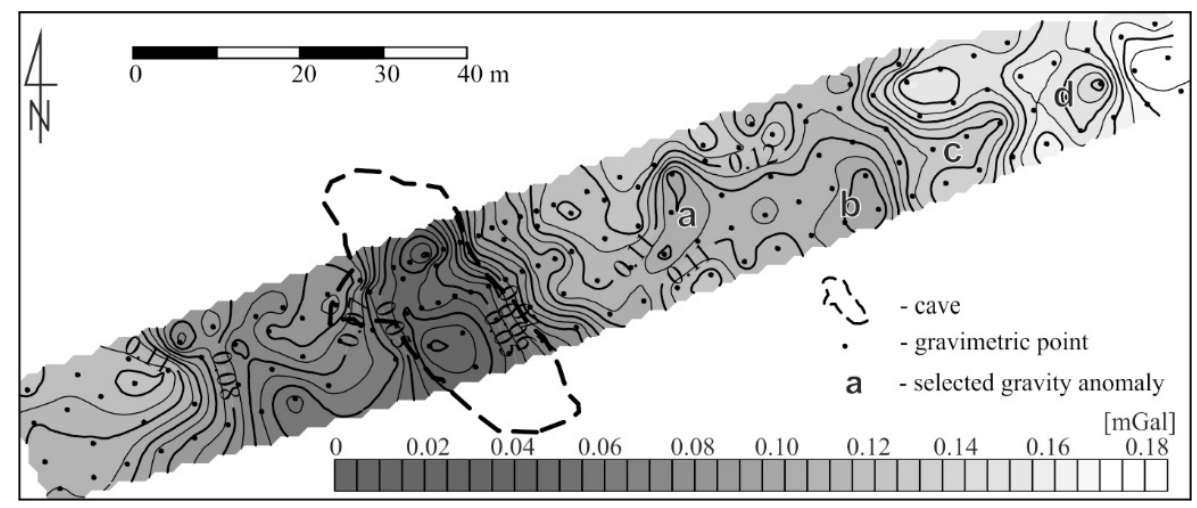

Fig. 8. Distribution of Bouguer anomalies with terrain correction

Last but not least, the correction of "Cave in Siesławice" was included. This has caused significant changes in the distribution of anomalies in the western part of the study area and practically remained unchanged in the rest of this area (Fig. 9).

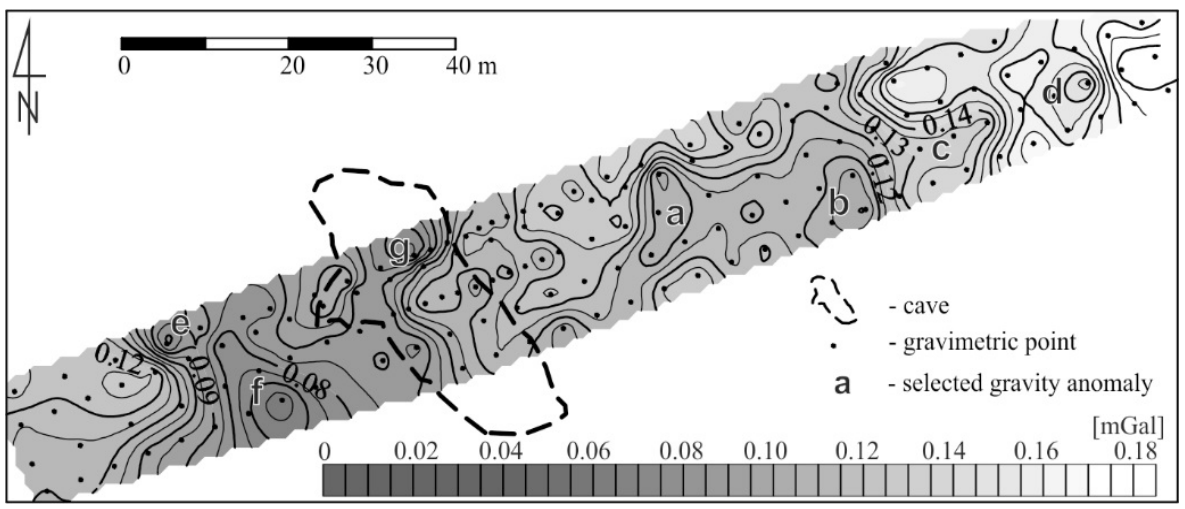

Fig. 9. Distribution of Bouguer anomalies with terrain correction and "cave correction"

Once all the corrections have been taken into account, the final interpretation of the results could be carried out. There is no doubt that the studied area was subject to strong karst phenomena. This is evident in complicated distribution of Bouguer anomalies. Undoubtedly, the $\mathrm{a}, \mathrm{b}, \mathrm{c}$ and $\mathrm{d}$ anomalies were derived from small, shallow voids or hollows in a gypsum filled with regolith. The $\mathrm{a}$ and $\mathrm{b}$ anomalies were located in a largest relatively negative anomaly, which may derived from a geater, deeper located void of small height.

However, the most interesting large-scale anomaly was located in the west part of the cave and partially above it. Its existence should be connected to two elements: the scarp and the cave (Figs. 3 and 9). The e and f anomalies were certainly associated with loosened zones and small voids within the scarp there were noticed fissures during the surveys. There were decreased anomaly values above the SW part of the cave, which indicates that there were small voids and loosened zones in the area. On this basis, it should be assumed that the stability of the cave in this area is at risk and threatens to collapse. In addition, the $\mathrm{g}$ 
anomaly indicates that also there is a decrease in bulk density in the northern part of the cave, which, in this case, should be associated with the existence of void. This fact makes the threat of cave collapse even more real.

\section{Conclusion}

Detailed gravimetric surveys require accurate geodetic measurements, and to achieve the required precision, modern measurement techniques should be used. In this work, terrestrial and airborne laser scanning (TSL and ASL) was used for the measurements. Data from these measurements have been used to create accurate digital terrain model (DTM) and spatial model of the cave. Thanks to that it was possible to eliminate their gravity influence with better accuracy.

The result of gravimetric surveys, in the form of Bouguer anomaly, showed a high concentration of karst phenomena in the studied region. Removing interfering or unnecessary information from gravimetric measurements has also shown that cave stability is at risk. It is very likely to collapse.

In conclusion, it can be said that the use of modern, precise geodetic measurements allows for better localization of even small, near-surface density changes and their accuracy significantly increases the credibility of gravimetric interpretation.

\section{References}

1. T. Gołębiowski, S. Porzucek, B. Pasierb, Ambiguities in geophysical interpretation during fracture detection-case study from a limestone quarry (Lower Silesia Region, Poland). Near surface geophysics, 14, 4, pp. 371-384 (2016)

2. W. Gruszczyński, W. Matwij, P. Ćwiąkała, Comparison of low-altitude UAV photogrammetry with terrestrial laser scanning as data-source methods for terrain covered in low vegetation. ISPRS Journal of Photogrammetry and Remote Sensing, 126, pp. 168-179 (2017)

3. J. Gubała, A. Kasza, J. Urban, Jaskinie Niecki Nidziańskiej. Wyd. PTPNoZ, Warszawa (1998)

4. Z. Fajklewicz, Geofizyka stosowana. Wyd. Nauk Technicznych AGH, Kraków (2008)

5. A. Kasprzyk, Lothofacies and sedimentation of the badenian (Middle Miocen) gypsum in the northern part of Carphatian Foredeep, Southern Poland. Annales Societatis Geologorum Poloniae, 63, pp. 33-84 (1993)

6. T. Lipecki, W. Jaśkowski, W. Gruszczyński, K. Matwij, W. Matwij, P. Ulmaniec, Inventory of the geometric condition of inanimate nature reserve Crystal Caves in „Wieliczka” Salt Mine. Acta Geodaetica et Geophysica Hungarica, 51, pp. 257-272, (2016)

7. M. Łój, T. Gołębiowski, S. Porzucek, Geophysical surveys and modelling for recognizing of gypsum karst. Geoinformatica Polonica, 13, pp. 83-97 (2014)

8. M. Łój, Microgravity monitoring discontinuous terrain deformation in a selected area of shallow coal extraction. Conference: 14th International Multidisciplinary Scientific Geoconference (SGEM) Location: Albena, Bulgaria (2014)

9. I. Walaszczyk, Turonian through Santonian deposit of the Central Polish Uplands, their facies development, inoceramid paleontologice and stratigraphy. Acta Geologica Polonica, 42, 1-2, pp. 1-122 (1992)

10. B.W.Wołoszyn, Jaskinie Zespołu Parków Krajobrazowych Ponidzia. Studia Ośr. Dok. Fizjogr. 18, pp. 275-341 (1990) 